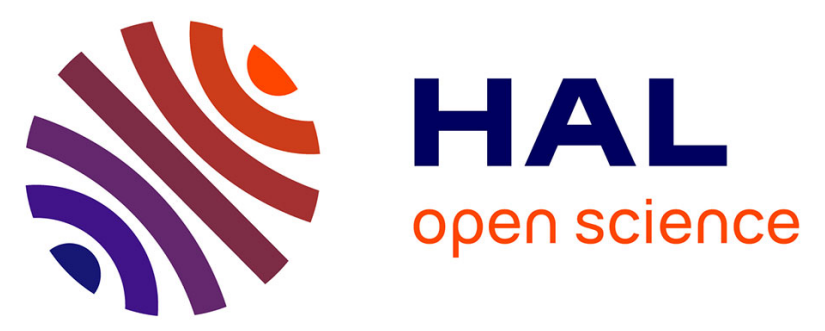

\title{
DUAL CUT-OFF TRANSIENT ELASTOGRAPHY TO ASSESS LIVER FIBROSIS IN CHRONIC HEPATITIS B: A COHORT STUDY WITH INTERNAL VALIDATION
}

\author{
Mauro Viganò, Silvia Paggi, Pietro Lampertico, Mirella Fraquelli, Sara \\ Massironi, Guido Ronchi, Cristina Rigamonti, Dario Conte, Massimo Colombo
}

\section{To cite this version:}

Mauro Viganò, Silvia Paggi, Pietro Lampertico, Mirella Fraquelli, Sara Massironi, et al.. DUAL CUT-OFF TRANSIENT ELASTOGRAPHY TO ASSESS LIVER FIBROSIS IN CHRONIC HEPATITIS B: A COHORT STUDY WITH INTERNAL VALIDATION. Alimentary Pharmacology and Therapeutics, 2011, 34 (3), pp.353. 10.1111/j.1365-2036.2011.04722.x . hal-00646925

\section{HAL Id: hal-00646925 https://hal.science/hal-00646925}

Submitted on 1 Dec 2011

HAL is a multi-disciplinary open access archive for the deposit and dissemination of scientific research documents, whether they are published or not. The documents may come from teaching and research institutions in France or abroad, or from public or private research centers.
L'archive ouverte pluridisciplinaire HAL, est destinée au dépôt et à la diffusion de documents scientifiques de niveau recherche, publiés ou non, émanant des établissements d'enseignement et de recherche français ou étrangers, des laboratoires publics ou privés. 


\begin{tabular}{l}
\hline Alimentary Pharmacology \\
\hline \& Therapeutics \\
\hline
\end{tabular}

\section{DUAL CUT-OFF TRANSIENT ELASTOGRAPHY TO ASSESS LIVER FIBROSIS IN CHRONIC HEPATITIS B: A COHORT STUDY WITH INTERNAL VALIDATION}

\begin{tabular}{|c|c|}
\hline Journal: & Alimentary Pharmacology \& Therapeutics \\
\hline Manuscript ID: & APT-0116-2011.R1 \\
\hline Wiley - Manuscript type: & Original Scientific Paper \\
\hline $\begin{array}{r}\text { Date Submitted by the } \\
\text { Author: }\end{array}$ & 11-Apr-2011 \\
\hline Complete List of Authors: & $\begin{array}{l}\text { Viganò, Mauro; Fondazione IRCCS Ca' Granda Ospedale Maggiore } \\
\text { Policlinico, Università degli Studi di Milano, I Gastroenterology Unit, } \\
\text { Department of Medicine } \\
\text { Paggi, Silvia; Fondazione IRCCS Ca' Granda Ospedale Maggiore } \\
\text { Policlinico, Università degli Studi di Milano, II Gastroenterology } \\
\text { Unit, Department of Medicine } \\
\text { Lampertico, Pietro; Fondazione IRCCS Ca' Granda Ospedale } \\
\text { Maggiore Policlinico, Università degli Studi di Milano, I } \\
\text { Gastroenterology Unit, Department of Medicine } \\
\text { Fraquelli, Mirella; Fondazione IRCCS Ca' Granda Ospedale Maggiore } \\
\text { Policlinico, Università degli Studi di Milano, II Gastroenterology } \\
\text { Unit, Department of Medicine } \\
\text { Massironi, Sara; Fondazione IRCCS Ca' Granda Ospedale Maggiore } \\
\text { Policlinico, Università degli Studi di Milano, II Gastroenterology } \\
\text { Unit, Department of Medicine } \\
\text { Ronchi, Guido; Fondazione IRCCS Ca' Granda Ospedale Maggiore } \\
\text { Policlinico, Università degli Studi di Milano, I Gastroenterology Unit, } \\
\text { Department of Medicine } \\
\text { Rigamonti, Cristina; Fondazione IRCCS Ca' Granda Ospedale } \\
\text { Maggiore Policlinico, Università degli Studi di Milano, I } \\
\text { Gastroenterology Unit, Department of Medicine } \\
\text { Conte, Dario; Fondazione IRCCS Ca' Granda Ospedale Maggiore } \\
\text { Policlinico, Università degli Studi di Milano, II Gastroenterology } \\
\text { Unit, Department of Medicine } \\
\text { Colombo, Massimo; Fondazione IRCCS Ca' Granda Ospedale } \\
\text { Maggiore Policlinico, Università degli Studi di Milano, I } \\
\text { Gastroenterology Unit, Department of Medicine }\end{array}$ \\
\hline Keywords: & $\begin{array}{l}\text { Hepatitis B < Hepatology, Liver biopsy < Hepatology, Liver fibrosis } \\
<\text { Hepatology, Viral hepatitis < Hepatology }\end{array}$ \\
\hline
\end{tabular}




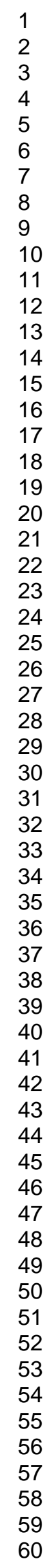

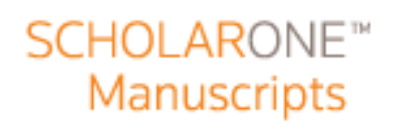




\section{DUAL CUT-OFF TRANSIENT ELASTOGRAPHY TO ASSESS LIVER FIBROSIS IN CHRONIC HEPATITIS B: A COHORT STUDY WITH INTERNAL VALIDATION}

Running title: Fibroscan in chronic hepatitis B

Mauro Viganò ${ }^{1,3}$, Silvia Paggi ${ }^{2}$, Pietro Lampertico ${ }^{1}$, Mirella Fraquelli ${ }^{2}$, Sara Massironi ${ }^{2}$, Guido Ronchi $^{1}$, Cristina Rigamonti ${ }^{1}$ Dario Conte ${ }^{2}$ and Massimo Colombo ${ }^{1}$.

1 “A. M. and A. Migliavacca" Center for Liver Disease, I Gastroenterology Unit, ${ }^{2}$ II Gastroenterology Unit, Department of Medicine, Fondazione IRCCS Ca' Granda Ospedale Maggiore Policlinico, Università degli Studi di Milano, Milan, Italy, ${ }^{3}$ Hepatology Unit, Ospedale San Giuseppe, Università degli Studi di Milano, Milan, Italy

Corresponding Author:

Mauro Viganò, MD PhD

Hepatology Unit, Ospedale San Giuseppe, Università degli Studi di Milano, Milan, Italy

Via S. Vittore 12 - 20123 Milan

ITALY

Tel: +39-0255035432

Fax: +39-0250320410

E-mail: mauro.vigano@tin.it 


\section{$\underline{\underline{\text { SUMMARY }}}$}

Background

Transient elastography (TE) has gained popularity to stage liver fibrosis in chronic viral hepatitis, however diagnostic cut-offs for severe fibrosis in chronic hepatitis B are poorly defined.

$\underline{\underline{\text { Aim }}}$

$\underline{\text { To evaluate an algorithm with two distinct cut-offs for positive and negative prediction of }}$ $\underline{\text { significant fibrosis and cirrhosis in chronic hepatitis B patients. }}$

$\underline{\underline{\text { Methods }}}$

Two cohorts of treatment-naïve patients with chronic hepatitis B (125 training and 92 validation) were consecutively and concurrently examined by percutaneous liver biopsy (LB) and TE. Fibrosis was staged by Metavir (significant fibrosis $=\mathrm{F} \geq 2$; cirrhosis $=\mathrm{F} 4$ ) in $\geq 2 \mathrm{~cm}$ long liver tissue cores. $\underline{\underline{\text { Results }}}$

$\underline{\text { A }>13.1 \mathrm{kPa} \text { positive and a } \leq 9.4 \mathrm{kPa} \text { negative cut-off for cirrhosis had a }>90 \% \text { sensitivity and }}$ specificity, with an accuracy of $94 \%$. The corresponding cut-offs for $\mathrm{F} \geq 2$ were $>9.4$ and $\leq 6.2 \mathrm{kPa}$, thus classifying $56 \%$ of patients with an overall accuracy of $90 \%$. In the validation cohort, F4 and F $\geq 2$ were predicted by the above TE cut-offs with an overall accuracy $>90 \%$. In 165 patients with higher than upper limit of normal transaminase activity (ALT) the dual cut-off algorithm of TE was as accurate as in the 52 patients with normal ALT values in the prediction and exclusion of cirrhosis, only.

Conclusions

A dual cut-off algorithm allowed for correctly classifying both significant fibrosis and cirrhosis in the majority of the patients with chronic hepatitis B, independently of ALT values, thus reducing the need of LB investigations.

Keywords: chronic hepatitis B, Fibroscan ${ }^{\circledR}$, liver fibrosis, liver stiffness transient elastography 
Viganò et al.

\section{INTRODUCTION}

The extension of liver fibrosis is a relevant predictor of chronic hepatitis B severity and therefore its evolution is of strategic importance in the decision making process of treatment with antivirals $(1,2)$. While the measure of liver fibrosis through percutaneous liver biopsy (LB) remains the standard of care, this procedure is limited by a low rate of acceptance, costs and risks of complications, especially in patients with advanced liver disease and coagulopathy who are at risk of bleeding (3) and is being progressively replaced by non invasive markers of liver fibrosis. This also happens since the diagnostic accuracy of LB is attenuated by sampling errors as well as by a significant rate of intra- and inter-observer variability (4,5). Not surprisingly, therefore a non invasive procedure like liver stiffness measurement by transient elastography (TE) has gained popularity in the management of patients with chronic hepatitis, with great emphasis in patients with chronic hepatitis $\mathrm{C}$, in whom has become a standard of care to assess severity of hepatitis (612). The accuracy of TE in chronic hepatitis B patients has been less accurately investigated since most studies were underpowered and included a limited number of patients with histologically documented or clinically established cirrhosis (13-26). Further, most of these studies lacked a concurrent $\mathrm{LB}$ and TE examination which is a prerequisite to weight the potential confounding role of hepatitis flares, that may unpredictably ensue during the course of the infection and challenge the diagnostic accuracy of TE $(15,18,22,26)$. This was clearly the case of a study in hepatitis B patients where liver stiffness increased from 1.2 to 4.4-fold during hepatitis flares, as compared to baseline values (15). Moreover, studies in hepatitis B patients whereas showing a significant correlation between liver stiffness and severity of liver disease, could not identify a similar TE cut-off value for the different stages of fibrosis $(13,14,18,23-25)$. We therefore asked ourselves whether the use of a dual cut-off TE algorithm in treatment-naïve patients, concurrently examined by LB would better predict and rule out significant fibrosis and cirrhosis in the course of chronic HBV infection, respectively, than the use of a single TE cut-off for each stage of fibrosis. 


\section{METHODS}

\section{Patients}

Between January 2007 and March 2010, 254 treatment-naïve patients with chronic hepatitis due to hepatitis B virus (HBV), defined as seropositivity for hepatitis B surface antigen (HBsAg), persistently or intermittently abnormal alanine aminotransferase (ALT) values and serum HBV DNA $>3 \log _{10} \mathrm{UI} / \mathrm{mL}$ lasting for $>6$ months, were consecutively referred for a LB to the Liver Center, Fondazione IRCCS Ca' Granda Ospedale Maggiore Policlinico, Milan. Patients with hepatitis C virus (HCV), hepatitis Delta virus (HDV), and human immunodeficiency virus (HIV) co-infections, other concomitant liver diseases, current or previous hepatic decompensation, current or previous antiviral treatment and/or an absolute contraindication to LB (platelets $<60 \times 10^{9} / \mathrm{L}$, INR > 1.35), were excluded.

Overall, 128 patients were recruited into a training cohort, who underwent a LB between January 2007 and July 2008 whereas a validation cohort of 96 patients underwent the same procedure between August 2008 and March 2010. Demographic and clinical data of all patients were recorded together with their past and/or current history of alcohol intake ( $>60 \mathrm{~g} /$ day for men and $>40 \mathrm{~g} /$ day for women as a marker of alcohol abuse). All patients gave their written consent to the study, which was approved by the local Ethics Committee.

\section{Serum assays}

Laboratory tests, including serum aspartate aminotransferase (AST) and ALT, albumin, total bilirubin, alkaline phosphatase, gamma glutamyl-transpeptidase, platelet count, the international normalized ratio (INR), were measured in all patients at the time of LB by standard laboratory procedures. Normal ALT were defined as $\leq 40$ IU/L [upper limit of normal (ULN)].

Serum HBsAg, hepatitis B e antigen (HBeAg), antibody to hepatitis B e antigen (anti-HBe) were detected by microparticle enzyme immunoassay (AXSYM, Abbot Laboratories, North Chicago, IL, USA). Serum HBV DNA was assessed by a real time PCR assay (COBAS TaqMan HBV, Roche 
Molecular Systems, Inc., Branchburg, NJ, US) with a lower limit of quantification of $12 \mathrm{IU} / \mathrm{mL}$ (1.1 $\left.\log _{10} \mathrm{IU} / \mathrm{mL}\right)$. Commercially available enzyme immunoassays were used to determine antibodies to HCV, HDV and HIV.

\section{Transient elastography by TE}

After an overnight fast, patients underwent a FibroScan ${ }^{\circledR}$ (Echosens, Paris, France) utilizing a 5$\mathrm{MHz}$ ultrasound transducer probe mounted on the axis of a vibrator that was operated by three experienced hepatologists (SP, MF, CR) who were blind to clinical, biochemical and histologic data $(1,27)$. Briefly, mild amplitude and low-frequency vibrations $(50 \mathrm{~Hz})$ are transmitted to the liver, thus inducing an elastic shear wave propagating through the underlying liver tissue. The velocity of the wave is directly related to tissue stiffness. The tip of the transducer was covered with a drop of gel and placed perpendicularly in the intercostal space with the patient lying in dorsal decubitus with the right arm in the maximal abduction. Under control time motion (TM) and A-mode, the operator chose a liver portion within the right liver lobe at least $6 \mathrm{~cm}$ thick, free of large vascular structures and gallbladder. Ten successful acquisitions were performed on each patient. The success rate (SR) was calculated as the ratio of the number of successful acquisitions over the total number of acquisitions. The median value, expressed in $\mathrm{kPa}$, was kept as representative of the liver stiffness. The manufacturer recommends that liver stiffness measurements was considered reliable by using the following criteria: 1) number of valid acquisitions at least 10;2) SR at least $60 \%$ and an interquartile range $<30 \%$.

\section{Percutaneous liver biopsy}

All patients underwent an ultrasound guided LB with a semiautomatic modified Menghini system (16 G, BioMol, Hospital Service, Pomezia, Italy, Philips iU22, Bothell, WA, USA), to stage severity of hepatitis. All the examinations were carried out by two highly experienced hepatologyst (SM and SP). While liver specimens were considered of adequate size if longer than $2 \mathrm{~cm}$, patients 
with a smaller specimen underwent repeated procedure during the same session. Five-micron thick sections of formalin-fixed, paraffin embedded liver tissue were stained with hematoxylin-eosin and Masson trichrome, and read by a liver pathologist (GR) blind to TE and clinical data. Grading and staging were evaluated according to METAVIR (staging F0 = fibrosis absent, F1= portal fibrosis without septa, F2 = portal fibrosis with few septa, F3 = severe fibrosis, F4 = cirrhosis) (28). Liver steatosis was quantified according to a published score system (29).

\section{Endpoint of the study}

The endpoint of the study was the definition of TE thresholds that accurately predict presence and absence of significant fibrosis ( $\mathrm{F} \geq 2)$ and cirrhosis (F4), respectively.

\section{Statistical analysis}

The summary receiver operating characteristics (SROC) curve, representing the relationship between sensitivity and 1 - specificity of TE, was calculated for the diagnosis of both significant fibrosis and cirrhosis. In the analysis of the SROC curve results, TE cut-off values with the best accuracy for both significant fibrosis and cirrhosis were identified. In detail, we identified a TE confirmatory threshold with specificity $>90 \%$ and positive likelihood ratio $(\mathrm{LR}+) \geq 10$ and a TE exclusion threshold with sensitivity $>90 \%$ and negative likelihood ratios (LR-) $\leq 0.1$, to rule in or out significant fibrosis and cirrhosis, respectively, as previously described (30,31). Finally, the correlation between TE values, histological features of hepatitis, including grading, staging and steatosis, and biochemical, virological and demographic features of the patients were evaluated by the correlation coefficient for quantitative variables (Spearman's correlation coefficient, significance level $\mathrm{p} \leq 0.05)$. Multivariate analysis was performed using multiple regressions on variables that were significant on univariate analysis. The diagnostic performances of the predictive model were finally tested in a temporal internal validation cohort. 
Viganò et al.

\section{RESULTS}

The LB procedures were uneventful in all cases, yielding a liver specimen of $2.7 \mathrm{~cm}$ median length (range 2-6 cm) and of $1 \mathrm{~mm}$ median thickness (range 1-1.2 mm), each sample including more than 12 portal tracts (range: $24-44)$. Four patients $(2 \%)$ needed a second passage to compensate for the first specimen which was not adequate $(<2 \mathrm{~cm}$ in length). Seven $(3 \%)$ overweight patients, $(\mathrm{BMI}>$ $25 \mathrm{Kg} / \mathrm{m}^{2}$, median $31 \mathrm{Kg} / \mathrm{m}^{2}$ ), 3 in the training and 4 in the validation cohort were excluded from analysis because they had unreliable TE results. The epidemiological and biochemical characteristics of the 217 evaluated patients are summarized in Table 1. Most of patients were HBeAg negative men, with normal body weight and no significant alcohol consumption. At the time of LB, 52 (24\%) patients had normal ALT, $144(66 \%)$ had ALT >1-5 times the ULN and 21 (10\%) had ALT > 5 times the ULN.

The degree of fibrosis was F0/1, F2, F3 and F4 in 89, 51, 33 and 44 patients. Significant fibrosis (F $\geq 2$ ) and cirrhosis (F4) were detected in $59 \%$ and $20 \%$ of patients, respectively. Baseline epidemiological, virological and biochemical features were similar between the training and validation cohort. TE values ranged from $3.4 \mathrm{kPa}$ to $62.0 \mathrm{kPa}$, with a median of $8.1 \mathrm{kPa}$. The median TE values were 5.4, 6.2, 8.1, 10 and $15.5 \mathrm{kPa}$ for F0, F1, F2, F3 and F4 (Figure 1). The distribution of liver stiffness values according to fibrosis stage in the training and in the validation cohort is reported in Table 2. Liver stiffness significantly correlated with BMI, platelets counts, AST, ALT, staging and steatosis (Table 3).

\section{The diagnosis of cirrhosis by TE}

In 125 patients evaluated in the training cohort, the SROC curve analysis (Figure 2a) showed an overall diagnostic accuracy for cirrhosis of $94.2 \%$ (95\% CI: 90.1-98.3\%). A single cut-off of 9.4 $\mathrm{kPa}$ predicted the histological diagnosis of cirrhosis in 106 patients (85\%), correctly classifying 20/20 patients with histological F4 with a sensitivity of 100\% (LR- 0.00). Since 19/105 patients (18\%) with F0-F3 had TE values $>9.4 \mathrm{kPa}$ (specificity of $82 \%, \mathrm{LR}+5.5$ ), this $9.4 \mathrm{kPa}$ cut-off was 
accurate enough to exclude but not to confirm cirrhosis ( $\mathrm{LR}+$ of 5.5). To overcome the limitations of the single TE cut-off, we developed an algorithm with two different TE cut-offs that accurately predicts and rules out significant fibrosis and cirrhosis. A cut-off of $13.1 \mathrm{kPa}$ instead confirmed F4, with a specificity of $93.3 \%$ (95\% CI: 86.7- 97.3\%), a LR+ of 11.2 and an overall accuracy of $90 \%$, since it correctly classified 113 out of 125 patients (90\%) yielding a correct identification of cirrhosis in $15 / 20$ patients with a sensitivity of $75 \%$ (LR- 0.3), 5 F4 patients having TE values $\leq$ $13.1 \mathrm{kPa}$ (false negatives). Among 22 patients with $>13.1 \mathrm{kPa}(18 \%$ of the cohort), $\mathrm{F} 4$ could be correctly confirmed in 15 patients.

By a $\leq 9.4 \mathrm{kPa}$ cut-off, F4 was correctly ruled out in 86/86 patients, representing the $69 \%$ of the cohort. $13 \%$ of patients with TE values between 9.4 and $13.1 \mathrm{kPa}$, however, could not be confidently discriminated for the presence or absence of cirrhosis (Figure S1 online Supporting Information). The concurrent application of both cut-offs allowed to rule in and rule out cirrhosis in $\underline{87 \%(108 / 125) \text { of the patients, with an overall accuracy of } 94 \%(101 / 108) \text {. By intention to diagnose }}$ $\underline{108 \text { of } 128(84 \%) \text { patients were correctly classified. }}$

In 92 patients included in the validation cohort we assessed the accuracy of the dual TE cut-offs algorithm, the $\leq 9.4 \mathrm{kPa}$ TE cut off correctly classified 54/55 (98\%) patients as not having cirrhosis, with a sensitivity $96 \%$ and LR- of 0.05 .

Conversely, the $>13.1 \mathrm{kPa}$ TE cut-off correctly classified 16/18 (89\%) patients as having cirrhosis, with a specificity of $97 \%$ and $\mathrm{LR}+22.0$. The concurrent application of both cut-offs allowed to diagnose the presence and absence of cirrhosis in $79 \%$ of the patients, with an overall accuracy of $96 \%$ (Figure S2 online Supporting Information).

\section{The diagnosis of significant fibrosis by TE}

The SROC curve analysis (Figure 2b) showed an overall diagnostic accuracy for significant fibrosis of $85 \%$ (95\% CI: $77.4-90.7 \%$ ). A single cut-off of $8.7 \mathrm{kPa}$ provided the best diagnostic accuracy of TE allowing a correct diagnosis in $96 / 125$ patients (77\%), including the diagnosis of $\mathrm{F} \geq 2$ in $42 / 66$ 
$(64 \%)$ patients, with a sensitivity of $64 \%$ (LR- 0.40). Five out of 59 patients (8\%) without significant fibrosis, had TE values $>8.7 \mathrm{kPa}$ (false positives), with a specificity of $91.5 \%$ (LR+ 7.5). This single TE cut off was however not adequate either to confirm ( $\mathrm{LR}+<10$ ) or to exclude (LR- > 0.1) significant fibrosis, whereas diagnosis was possible using the same approach with two cut-off values, one with specificity $>90 \%$ and $\mathrm{LR}+\geq 10$ which did confirm, and one with sensitivity $>90 \%$ and LR- $\leq 0.1$ which did exclude the diagnosis. The best cut-off to exclude significant fibrosis was a TE value $<6.2 \mathrm{kPa}$, which correctly classified 62/66 (94\%) patients with a sensitivity of $94 \%$ (LR- 0.1) leaving misclassified 4 patients, only. 32/59 patients (54\%) without significant fibrosis had $>6.2 \mathrm{kPa}$ TE (false positives) with a specificity of $46 \%(\mathrm{LR}+1.7)$. Owing to its high sensitivity, the $6.2 \mathrm{kPa}$ cut-off is fit to exclude significant fibrosis, but it poorly predicts significant fibrosis (LR+ of 1.7).

Owing to high specificity, a TE value $>9.4 \mathrm{kPa}$ (specificity 93.3\%, 95\% CI: 86.7-97.3\%) was a good predictor of significant fibrosis, since it correctly classified 36/66 patients with a sensitivity of $55 \%$ (LR- 0.5). 56/59 patients without significant fibrosis had $\leq 9.4 \mathrm{kPa}$ TE (specificity 95\%, LR+ 11) with 3 patients (false positives) only misclassified.

Among the 31 patients with $\leq 6.2 \mathrm{kPa}$ (25\% of the cohort), significant fibrosis could be correctly ruled out in $27(87 \%)$, whereas in the 39 patients with $>9.4 \mathrm{kPa}$ (31\% of the cohort) significant fibrosis could be correctly confirmed in $36(92 \%)$ patients. The concurrent application of both cutoffs allowed to rule in and rule out significant fibrosis in $56 \%(70 / 125)$ of the patients, with an overall accuracy of $90 \%$, i.e. with a correct diagnosis in 63 of 70 patients (Figure S3 online Supporting Information). By intention to diagnose, 70 of 128 patients (55\%) were correctly classified. Conversely, the presence or absence of significant fibrosis could not be established in patients with cut-offs ranging form 6.2 to $9.4 \mathrm{kPa}$.

In the 92 patients of the validation cohort, the application of corresponding thresholds for significant fibrosis, i.e. $\leq 6.2 \mathrm{kPa}$ and $>9.4 \mathrm{kPa}$, correctly classified $72 \%$ of the patients, with an overall accuracy of $92 \%$ (Figure S4 online Supporting Information). 
Viganò et al.

\begin{abstract}
ALT levels and TE examination
To evaluate the potential effect of ALT values on the accuracy of this dual cut-off model, patients were reanalyzed according to ALT levels: 52 patients had ALT $\leq 1 \times$ ULN and 165 patients had $>1$ x ULN. The model was able to accurately confirm or exclude cirrhosis independently on ALT levels, whereas it was less accurate to correctly diagnose significant fibrosis $(F \geq 2)$ in patients with ALT $>1 \times$ ULN (Table 4).
\end{abstract}


Viganò et al.

\section{DISCUSSION}

We demonstrate the clinical usefulness of an algorithm based on two cut-off values of TE in patients with chronic hepatitis due to $\mathrm{HBV}$, since it accurately excluded or identified both significant liver fibrosis $(\mathrm{F} \geq 2)$ and cirrhosis ( $F 4)$ in patients who were concurrently examined by a percutaneous LB. The TE cut-off values of $\leq 9.4$ and $>13.1 \mathrm{kPa}$ were excellent negative and positive predictors of cirrhosis, respectively, being endowed with such a high sensitivity and specificity to potentially spare LB procedures in $83 \%$ of the patients examined. The performance of TE was subsequently validated in an internal validation set of patients who had similar demographic and clinical characteristics as the training set. Overall, the above described dual TE cut-off algorithm was more accurate than previously described single TE cut-offs in the prediction or exclusion of HBV-related cirrhosis $(13,18,24,25)$.

Obviously, the applicability of this dual cut-off strategy is largely dictated by the clinical scenario of HBV infection, i.e. the pre-test probabilities of cirrhosis in the population under study. In patients with a lower than $10 \%$ pre-test probability of cirrhosis, like young HBeAg seropositive patients with persistently normal ALT levels, a $\leq 9.4 \mathrm{kPa}$ value would definitely grant for absence of cirrhosis in virtually all patients, thus making histological examination of the liver unnecessary $(1,2)$. Conversely, in patients with a higher (10-30\%) pre-test probability of cirrhosis, like HBeAgnegative adults with persistently abnormal ALT levels, a $>13.1 \mathrm{kPa}$ value would fit the clinical needs of looking for the presence of cirrhosis, while minimizing the need for histological confirmation $(1,32)$. Needless to say, the identification of cirrhosis in patients with chronic hepatitis B bears important clinical implications that go beyond prognosis and treatment, since the presence of cirrhosis calls for secondary prevention of hepatocellular carcinoma through 6-month surveillance with abdominal ultrasound (33).

The non invasive identification of patients with significant liver fibrosis $(F \geq 2)$ bears most important clinical implications too, since the extent of liver fibrosis guides anti-HBV therapy $(2,34)$.

Using a negative predictor cut-off of $\leq 6.2 \mathrm{kPa}$ together with a positive predictor cut-off of $>9.4$ 
$\mathrm{kPa}$, a diagnosis of $\mathrm{F} \geq 2$ is achieved in $2 / 3$ of the patients, thus sparing a relevant numbers of LB procedures without affecting the overall diagnostic accuracy of the selection process. In patients with a low pre-test probability for $\mathrm{F} \geq 2$, like inactive $\mathrm{HBsAg}$ carriers, $\mathrm{a} \leq 6.2 \mathrm{kPa}$ cut-off could rule out significant fibrosis in virtually all patients. These findings are in line with a recently published study by Castera et al. where all inactive carriers of HBV had TE values lower than $5.8 \mathrm{kPa}(35)$. Whereas a $>9.4 \mathrm{kPa}$ cut-off accurately predicted $\mathrm{F} \geq 2$ in patients with a higher probability of significant fibrosis, like middle-aged $\mathrm{HBeAg}$ negative patients with persistently abnormal ALT levels (1).

One clinical benefit value of a TE algorithm based on dual cut-off is the ability to minimize the confounding effect of hepatitis flares in the assessment of liver fibrosis by TE, which biased previous studies based on a single TE cut-off, where a positive correlation between serum ALT levels and TE values, was constantly reported $(15,22, \underline{\underline{36}})$. In more than one study, in fact, patients with elevated serum ALT levels had higher TE values than patients with persistently normal ALT and similar degree of liver fibrosis $(15,18)$. Being our investigation a cross-sectional study, not a longitudinal assessment of TE values across ALT flares, we could not evaluate the interaction between hepatitis flares and TE values, whereas we showed that in advanced liver disease patients, serum ALT levels likely have little impact on TE measurements, whereas liver fibrosis plays a predominant role.

Although our predefined criteria of adequacy of LB was based on $20 \mathrm{~mm}$ cut-off, we acknowledge that quantification of liver fibrosis by LB examination might be compromised by suboptimal sampling of the liver, since $<2.5 \mathrm{~cm}$ liver cores still underestimate the severity of liver fibrosis by $25 \%(4,5)$. Along this line, was the finding of 6 of 7 patients with F3 having TE values $>13.1 \mathrm{kPa}$.

We acknowledge that our diagnostic algorithm based on dual cut-off values of TE needs to be externally validated prior to be confidently applied to patients with chronic hepatitis B, with the aim of sparing histological investigations, especially considering the many virological and host characteristics that may impact TE accuracy. In fact, in the face of our study showing excellent 
reliable TE results at $97 \%$, there is a recent study in France reporting lower rates (84\%) of reliable TE results, mostly related to obesity $(\underline{\underline{37}})$. Differences in the rates of performance with TE could also depend on the prevalence of patients with alcohol abuse or steatosis, both known to impact on the diagnostic accuracy of TE, whereas our study based on dual TE cut-off apparently was not affected by these variables.

We wish to outline that patients included in the present study, were active carriers of $\mathrm{HBV}$, including the 4 patients with both ALT lower than the upper limit of normal and serum HBV DNA $<2.000 \mathrm{IU} / \mathrm{mL}$ at the time of LB, who infact, have had higher liver enzymes and viremia levels during the pre-study screening. We wish also to outline that clinical application of TE was not affected by the exclusion of patients sited at the extreme wings of the clinical spectrum of $\mathrm{HBV}$, like those with minimal histological changes of the liver, and those with advanced or decompensated cirrhosis. Indeed, inactive HBV carriers are not eligible to LB, whereas patients with advanced cirrhosis due to HBV were unfit to LB examination because of excessive bleeding risk and could be easily identified on clinical grounds $(2,34, \underline{\underline{38-44}})$.

Despite TE cut-offs are influenced by the uneven distribution of fibrosis stages (spectrum bias) in patients referred for LB $(\underline{\underline{45}})$, the prevalence of significant fibrosis $(\mathrm{F} \geq 2)$ and cirrhosis $(\mathrm{F} 4)$ in our cohort was similar as in previous studies ultimately being representative of the spectrum of histological stages of HBV patients undergoing LB in any referral centre (18-21).

We acknowledge that serum tests to assess liver fibrosis in patients with viral hepatitis are even more user friendly than TE and therefore present as theoretically in competition with TE to assess patients with chronic hepatitis B, we wish to remind, however, that serum tests for liver fibrosis are less discriminating than TE in patients with chronic hepatitis $\mathrm{B}(\underline{\underline{39,46,47}})$, due to their limited sensitivity for excluding cirrhosis, even when serum markers of fibrosis are applied in different combinations with hematological or biochemical parameters $(\underline{\underline{48}})$.

In conclusion, we prospectively tested the clinical value of a diagnostic algorithm based on two TE cut-offs that allows for the exclusion and confirmation of both significant fibrosis $(\mathrm{F} \geq 2)$ and 
Viganò et al.

cirrhosis (F4) in patients with chronic hepatitis B, respectively. Compared to a single TE cut-off approach, the dual TE cut-off algorithm has remarkable accuracy independently of ALT levels, therefore standing as a user friendly option for staging fibrosis and refining indications to LB examination in chronic hepatitis B patients. 


\section{DISCLOSURES}

Massimo Colombo

Grant and Research support: MSD, ROCHE, GILEAD;

Advisory committees: BRISTOL-MEYERS-SQUIBB, MSD, ROCHE, NOVARTIS, GILEAD, VERTEX, TIBOTEC, ACHILLION;

Speaking and Teaching: BRISTOL-MEYERS-SQUIBB, MSD, ROCHE, NOVARTIS, GILEAD, VERTEX.

Pietro Lampertico

Advisory Board/Speaker Bureau: BRISTOL-MEYERS-SQUIBB, ROCHE, NOVARTIS, GILEAD, GSK.

The other authors have no competing interest. 


\section{REFERENCES}

1. Fattovich G, Bortolotti F, Donato F. Natural history of chronic hepatitis B: special emphasis on disease progression and prognostic factors. J Hepatol 2008; 48: 335-52.

2. European Association For The Study Of The Liver. EASL Clinical Practice Guidelines: management of chronic hepatitis B. J Hepatol 2009; 50: 227-42.

3. Rockey DC, Caldwell SH, Goodman ZD, et al. American Association for the Study of Liver Diseases. Liver biopsy. Hepatology 2009; 49: 1017-44.

4. Bedossa P, Dargere D, Paradis V. Sampling variability of liver fibrosis in chronic hepatitis C. Hepatology 2003; 38: 1449-57.

5. Bedossa P, Carrat F. Liver biopsy: the best, not the gold standard. J Hepatol 2009; 50: 1-3.

6. Ziol M, Handra-Luca A, Kettaneh A, et al. Noninvasive assessment of liver fibrosis by measurement of stiffness in patients with chronic hepatitis C. Hepatology 2005; 41: 48-54.

7. Castera L, Vergniol J, Foucher J, et al. Prospective comparison of transient elastography, Fibrotest, APRI, and liver biopsy for the assessment of fibrosis in chronic hepatitis C. Gastroenterology 2005; 128: 343-50.

8. Foucher J, Chanteloup E, Vergniol J, et al. Diagnosis of cirrhosis by transient elastography (FibroScan): a prospective study. Gut 2006; 55: 403-08.

9. Ganne-Carrie N, Ziol M, de Ledinghen V, et al. Accuracy of liver stiffness measurement for the diagnosis of cirrhosis in patients with chronic liver diseases. Hepatology 2006; 44: 1511-17.

10. Corpechot C, El Naggar A, Poujol-Robert A, et al. Assessment of biliary fibrosis by transient elastography in patients with PBC and PSC. Hepatology 2006; 43: 1118-24.

11. Fraquelli M, Rigamonti C, Casazza G, et al. Reproducibility of transient elastography in the evaluation of liver fibrosis in patients with chronic liver disease. Gut 2007; 56: 968-73.

12. Friedrich-Rust M, Ong MF, Martens S, et al. Performance of transient elastography for the staging of liver fibrosis: a meta-analysis. Gastroenterology 2008; 134: 960-974. 
13. Marcellin P, Ziol M, Bedossa P, et al. Non-invasive assessment of liver fibrosis by stiffness measurement in patients with chronic hepatitis B. Liver Int 2009; 29: 242-47.

14. Fung J, Lai CL, Fong DY. Correlation of liver biochemistry with liver stiffness in chronic hepatitis B and development of a predictive model for liver fibrosis. Liver Int 2008; 28 : 1408-16.

15. Oliveri F, Coco B, Ciccorossi P, et al. Liver stiffness in the hepatitis B virus carrier: A noninvasive marker of liver disease influenced by the pattern of transaminases. World $\mathrm{J}$ Gastroenterol 2008; 14: 6154-62.

16. Ogawa E, Furusyo N, Toyoda K, et al. Transient elastography for patients with chronic hepatitis $\mathrm{B}$ and $\mathrm{C}$ virus infection: Non-invasive, quantitative assessment of liver fibrosis. Hepatol Res 2007; 37: 1002-10.

17. Maimone S, Calvaruso V, Pleguezuelo M, et al. An evaluation of transient elastography in the discrimination of HBeAg-negative disease from inactive hepatitis B carriers. J Viral Hepat 2009; 16: 769-74.

18. Chan HL, Wong GL, Choi PC, et al. Alanine aminotransferase-based algorithms of liver stiffness measurement by transient elastography (Fibroscan) for liver fibrosis in chronic hepatitis B. J Viral Hepat 2009; 16: 36-44.

19. Fung J, Lai CL, Chan SC, et al. Correlation of liver stiffness and histological features in healthy persons and in patients with occult hepatitis B, chronic active hepatitis B, or hepatitis B cirrhosis. Am J Gastroenterol 2010; 105: 1116-22.

20. Wong GL, Wong VW, Choi PC, et al. Clinical factors associated with liver stiffness in hepatitis B e antigen-positive chronic hepatitis B patients. Clin Gastroenterol Hepatol 2009; 7: 227-33.

21. Wong GL, Wong VW, Choi PC, et al. Development of a non-invasive algorithm with transient elastography (Fibroscan) and serum test formula for advanced liver fibrosis in chronic hepatitis B. Aliment Pharmacol Ther 2010; 31: 1095-103. 
22. Coco B, Oliveri F, Maina AM, et al. Transient elastography: a new surrogate marker of liver fibrosis influenced by major changes of transaminases. J Viral Hepat 2007; 14: 36069.

23. Sporea I, Sirli R, Deleanu A, et al. Liver stiffness measurements in patients with HBV vs HCV chronic hepatitis: a comparative study. World J Gastroenterol. 2010; 16: 4832-7

24. Chang PE, Lui HF, Chau YP, et al. Prospective evaluation of transient elastography for the diagnosis of hepatic fibrosis in Asians: comparison with liver biopsy and aspartate transaminase platelet ratio index. Aliment Pharmacol Ther 2008; 28: 51-61

25. Kim do Y, Kim SU, Ahn SH, et al. Usefulness of FibroScan for detection of early compensated liver cirrhosis in chronic hepatitis B. Dig Dis Sci 2009; 54: 1758-1763

26. Wong GL, Wong VW, Choi PC, et al.. Increased liver stiffness measurement by transient elastography in severe acute exacerbation of chronic hepatitis B. J Gastroenterol Hepatol 2009; 24: 1002-1007

27. Rigamonti C, Donato MF, Fraquelli M, et al. Transient elastography predicts fibrosis progression in patients with recurrent hepatitis C after liver transplantation. Gut 2008; 57: $821-27$

28. Poynard T, Bedossa P, Opolon P. Natural history of liver fibrosis progression in patients with chronic hepatitis C. The OBSVIRC, METAVIR, CLINIVIR, and DOSVIRC groups. Lancet 1997; 349: 825-32.

29. Kleiner DE, Brunt EM, Van Natta M, et al. Design and validation of a histological scoring system for nonalcoholic fatty liver disease. Hepatology 2005; 41: 1313-21.

30. Black ER, Panzer RJ, Mayewski RJ, et al. Characteristics of diagnostic tests and principles for their use in quantitative decision making in diagnostic strategies for common medical problems. In: Black ER, Bordley DR, Tape TG, Panzer RJ. Diagnostic strategies of common medical problems. Philadelphia: American College of Physicians 1999: 1-17. 
31. Lijmer JG, Mol BW, Heisterkamp S, et al. Empirical evidence of design-related bias in studies of diagnostic tests. JAMA 1999; 282: 1061-66.

32. Wong GL, Wong VW, Choi PC, et al. Evaluation of alanine transaminase and hepatitis B virus DNA to predict liver cirrhosis in hepatitis B e antigen-negative chronic hepatitis B using transient elastography. Am J Gastroenterol 2008; 103: 3071-81.

33. Bruix J, Sherman M; Practice Guidelines Committee, American Association for the Study of Liver Diseases. Management of hepatocellular carcinoma. Hepatology 2005; 42: 120836.

34. Lok AS, McMahon BJ. Chronic hepatitis B: update 2009. Hepatology 2009; 50: 1-36.

35. Castéra L, Bernard PH, Le Bail B, et al. Transient elastography and biomarkers for liver fibrosis assessment and follow-up of inactive hepatitis B carriers. Aliment Pharmacol Ther. 2011;33:455-65.

36. Arena U, Vizzuti F, Corti G, et al. Acute viral hepatitis increases liver stiffness values measured by transient elastography. Hepatology 2008; 47: 380-84.

37. Castéra L, Foucher J, Bernard PH, et al. Pitfalls of liver stiffness measurement: a 5-year prospective study of 13,369 examinations. Hepatology 2010; 51: 828-35.

38. Hui AY, Liew CT, Go MY, et al. Quantitative assessment of fibrosis in liver biopsies from patients with chronic hepatitis B. Liver Int 2004; 24: 611-18.

39. Chrysanthos NV, Papatheodoridis GV, Savvas S, et al. Aspartate aminotransferase to platelet ratio index for fibrosis evaluation in chronic viral hepatitis. Eur J Gastroentrol Hepatol 2006; 18: 389-96.

40. Myers RP, Tainturier MH, Ratziu V, et al. Prediction of liver histological lesion with biochemical markers in patients with chronic hepatitis B. J Hepatol 2003; 39: 222-30.

41. Zeng MD, Lu LG, Mao YM, et al. Prediction of significant fibrosis in HBeAg positive patients with chronic hepatitis B infection by a non-invasive model. Hepatology 2005; 42: 
42. Wai CT, Cheng CL, Wee A, et al. Non-invasive models for predicting histology in patients with chronic hepatitis B. Liver Int 2006; 26: 666-72.

43. Hung $\mathrm{CH}$, Lu SN, Wang JH, et al. Correlation between ultrasonographic ad pathologic diagnoses of hepatitis B and C virus-related cirrhosis. J Gastroenterol 2003; 38: 153-57

44. Colli A, Fraquelli M, Andreoletti M, et al. Severe liver fibrosis or cirrhosis accuracy of US for the detection - analysis of 300 cases. Radiology 2003; 227: 89-94.

45. Poynard T, Halfon P, Castera L, et al. Standardization of ROC curve areas for diagnostic evaluation of liver fibrosis markers based on prevalences of fibrosis stages. Clin Chem 2007; 53: 1615-22.

46. Hui AY, Chan HL, Wong VW, et al. Identification of chronic hepatitis B patients without significant liver fibrosis by a simple noninvasive predictive model. Am J Gastroenterol 2005; 100: 616-23.

47. Poynard T, Zoulim F, Ratziu V, et al. Longitudinal assessment of histology surrogate markers (FibroTest-ActiTest) during lamivudine therapy in patients with chronic hepatitis hepatitis B infection. Am J Gastroenterol 2005; 100: 1970-80.

48. Castera L, Le Bail B, Roudot-Thoraval F, et al. Early detection in routine clinical practice of cirrhosis and oesophageal varices in chronic hepatitis $\mathrm{C}$ : Comparison of transient elastography (FibroScan) with standard laboratory tests and non-invasive scores. J Hepatol 2009; 50: 59-68. 
Viganò et al.

Table 1. Epidemiological, virological and biochemical characteristics of the 217 patients with adequate TE results included in the training $($ No. $=125)$ and validation $($ No. $=92)$ cohorts.

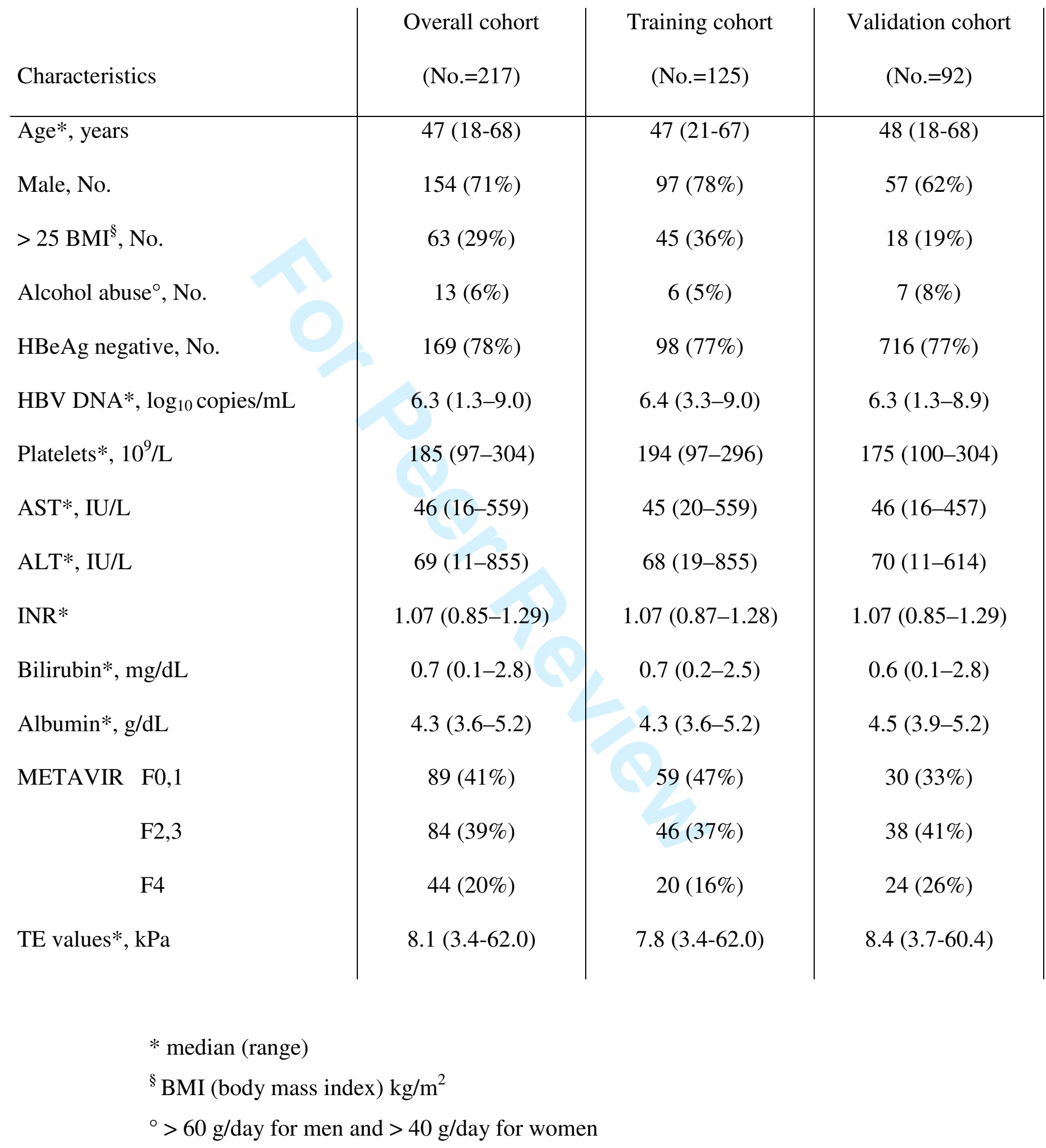


Viganò et al.

Table 2. Distribution of liver stiffness values $(\mathrm{kPa})$ using TE in each METAVIR fibrosis stage in a the training (No.=125), validation (No.=92) and overall (No.=217) cohort

$\underline{\text { Training cohort }}$

\begin{tabular}{|l|c|c|c|c|c|}
\hline \multirow{2}{*}{$\begin{array}{c}\text { TE values } \\
(\mathrm{kPa})\end{array}$} & \multicolumn{5}{|c|}{ METAVIR } \\
\cline { 2 - 6 } & $\begin{array}{c}\text { F 0 } \\
\text { (No.=16) }\end{array}$ & $\begin{array}{c}\text { F 1 } \\
(\text { No.=43) }\end{array}$ & $\begin{array}{c}\text { F 2 } \\
\text { No.=32) }\end{array}$ & $\begin{array}{c}\text { F 3 } \\
(\text { No.=14 })\end{array}$ & $\begin{array}{c}\text { F 4 } \\
\text { (No.=20 })\end{array}$ \\
\hline $3.4-5$ & 5 & 2 & 1 & 0 & 0 \\
\hline $5.1-10$ & 10 & 38 & 24 & 5 & 3 \\
\hline $10.1-15$ & 1 & 2 & 6 & 5 & 7 \\
\hline$>15$ & 0 & 1 & 1 & 4 & 10 \\
\hline Median & 5.6 & 6.6 & 8.2 & 12.4 & 16.5 \\
\hline
\end{tabular}

$\underline{\text { Validation cohort }}$

\begin{tabular}{|l|c|c|c|c|c|}
\hline \multirow{2}{*}{$\begin{array}{c}\text { TE values } \\
(\mathrm{kPa})\end{array}$} & \multicolumn{5}{|c|}{ METAVIR } \\
\cline { 2 - 6 } & $\begin{array}{c}\text { F 0 } \\
(\text { No.=12) }\end{array}$ & $\begin{array}{c}\text { F 1 } \\
(\text { No.=18) }\end{array}$ & $\begin{array}{c}\text { F 2 } \\
(\text { No.=19) }\end{array}$ & $\begin{array}{c}\text { F 3 } \\
(\text { No.=19) }\end{array}$ & $\begin{array}{c}\text { F 4 } \\
\text { (No.=24) }\end{array}$ \\
\hline $3.4-5$ & 4 & 4 & 0 & 0 & 0 \\
\hline $5.1-10$ & 8 & 13 & 18 & 13 & 1 \\
\hline $10.1-15$ & 0 & 0 & 1 & 5 & 11 \\
\hline$>15$ & 0 & 1 & 0 & 1 & 12 \\
\hline Median & 5.3 & 5.7 & 8.1 & 9.8 & 15.0 \\
\hline
\end{tabular}

$\underline{\text { Overall cohort }}$

\begin{tabular}{|l|c|c|c|c|c|}
\hline \multirow{2}{*}{$\begin{array}{c}\text { TE values } \\
(\mathrm{kPa})\end{array}$} & \multicolumn{5}{|c|}{ METAVIR } \\
\cline { 2 - 6 } & $\begin{array}{c}\text { F 0 } \\
(\text { No.=28) }\end{array}$ & $\begin{array}{c}\text { F 1 } \\
(\text { No.=61) }\end{array}$ & $\begin{array}{c}\text { F 2 } \\
\text { No.=51) }\end{array}$ & $\begin{array}{c}\text { F 3 } \\
(\text { No.=33 })\end{array}$ & $\begin{array}{c}\text { F 4 } \\
\text { (No.=44) }\end{array}$ \\
\hline $3.4-5$ & 9 & 6 & 1 & 0 & 0 \\
\hline $5.1-10$ & 18 & 51 & 42 & 18 & 4 \\
\hline $10.1-15$ & 1 & 2 & 7 & 10 & 18 \\
\hline$>15$ & 0 & 2 & 1 & 45 & 22 \\
\hline Median & 5.4 & 6.2 & 8.1 & 10.0 & 15.5 \\
\hline
\end{tabular}


Viganò et al.

Table 3. Multiple regression between liver stiffness values (kPa) using TE and histological, biochemical and demographic features of the 217 patients in study.

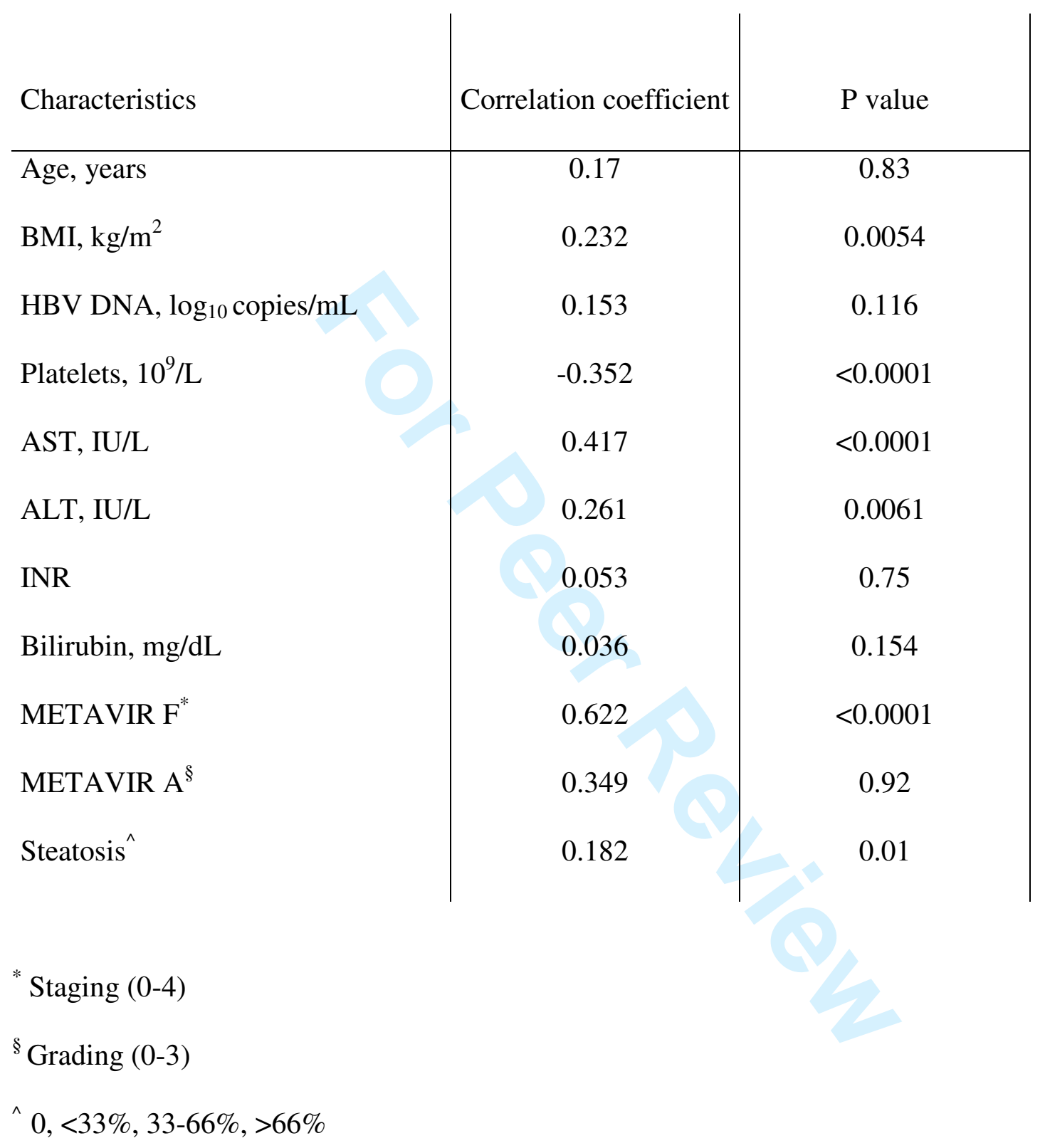


Viganò et al.

Table 4. Diagnostic performances of different TE cut-offs vs concurrent application of a two cut-off algorithm to exclude and confirm histological diagnosis of significant fibrosis $(F \geq 2)$ or cirrhosis (F4).

\begin{tabular}{|c|c|c|c|c|}
\hline & $\begin{array}{c}\text { TE cut-off } \\
(\mathrm{kPa})\end{array}$ & $\begin{array}{l}\text { Overall cohort } \\
\qquad(\mathrm{n}=217)\end{array}$ & $\begin{array}{c}\text { Patients with } \\
\text { ALT } \leq 1 \times \text { ULN } \\
(\text { No. }=52)\end{array}$ & $\begin{array}{c}\text { Patients with } \\
\text { ALT }>1 \times \text { ULN } \\
\quad(\text { No. }=165)\end{array}$ \\
\hline $\begin{array}{l}\text { Sensitivity to exclude } \\
\text { cirrhosis }\end{array}$ & $\leq 9.4$ & $98 \%(\mathrm{LR}-=0.02)$ & $100 \%(\mathrm{LR}-=0)$ & $97 \%(\mathrm{LR}-=0.04)$ \\
\hline $\begin{array}{l}\text { Specificity to confirm } \\
\text { cirrhosis }\end{array}$ & $>13.1$ & $95 \%(\mathrm{LR}+=14)$ & $97 \%(\mathrm{LR}+=22)$ & $94 \%(\mathrm{LR}+=12)$ \\
\hline $\begin{array}{l}\text { Overall accuracy to } \\
\text { exclude and confirm } \\
\text { cirrhosis }\end{array}$ & $\begin{array}{c}\leq 9.4 \\
\text { and } \\
>13.1\end{array}$ & $94 \%$ & $97 \%$ & $93 \%$ \\
\hline $\begin{array}{l}\text { Sensitivity to exclude } \\
\text { significant fibrosis }\end{array}$ & $\leq 6.2$ & $94 \%(\mathrm{LR}-=0.10)$ & $100 \%(\mathrm{LR}-=0)$ & $94 \%(\mathrm{LR}-=0.3)$ \\
\hline $\begin{array}{l}\text { Specificity to confirm } \\
\text { significant fibrosis }\end{array}$ & $>9.4$ & $96 \%(\mathrm{LR}+=14)$ & $100 \%(\mathrm{LR}+=\infty)$ & $93 \%(\mathrm{LR}+=7.5)$ \\
\hline $\begin{array}{l}\text { Overall accuracy to } \\
\text { exclude and confirm } \\
\text { significant fibrosis }\end{array}$ & $\begin{array}{l}\leq 6.2 \\
\text { and } \\
>9.4\end{array}$ & $91 \%$ & $100 \%$ & $90 \%$ \\
\hline
\end{tabular}




\section{FIGURE LEGEND}

Figure 1. Distribution of liver stiffness $(\mathrm{kPa})$ values using transient elastography according to METAVIR staging score in 217 patients.

Figure 2. A) ROC curve representing the relationship between sensitivity and 1 - specificity of liver stiffness for the diagnosis of cirrhosis (F4). The white square represents the cutoff value with the highest accuracy, i.e. $9.4 \mathrm{kPa}$ (sensitivity $100 \%$, specificity $82 \%$ ).

B) ROC curve representing the relationship between sensitivity and 1 - specificity of liver stiffness for significant fibrosis $(\mathrm{F} \geq 2)$. The white square represents cut-off value with the highest accuracy, i.e. $8.7 \mathrm{kPa}$ (sensitivity $63.6 \%$, specificity $91.5 \%$ ).

\section{LEGEND FOR SUPPLEMENTARY FIGURES}

Supplementary Figure S1. Training cohort of 125 patients. Diagnostic algorithm to confirm or exclude cirrhosis (F4) by transient elastography. Post-test probability of cirrhosis is the proportion of patients with histological diagnosis of cirrhosis according to transient elastography classification.

Supplementary Figure S2. Validation cohort of 92 patients. Diagnostic algorithm to confirm or exclude cirrhosis (F4) by transient elastography. Post-test probability of cirrhosis is the proportion of patients with histological diagnosis of cirrhosis according to transient elastography classification.

Supplementary Figure S3. Training cohort of 125 patients. Diagnostic algorithm to confirm or exclude significant fibrosis $(\mathrm{F} \geq 2)$ by transient elastography. Post-test probability of significant fibrosis is the proportion of patients with histological diagnosis of $\mathrm{F} \geq 2$ according to transient elastography classification.

Supplementary Figure S4. Validation cohort of 92 patients. Diagnostic algorithm to confirm or exclude significant fibrosis $(\mathrm{F} \geq 2)$ by transient elastography. Post-test probability of 
significant fibrosis is the proportion of patients with histological diagnosis of $F \geq 2$ according to transient elastography classification. 
Figure 1

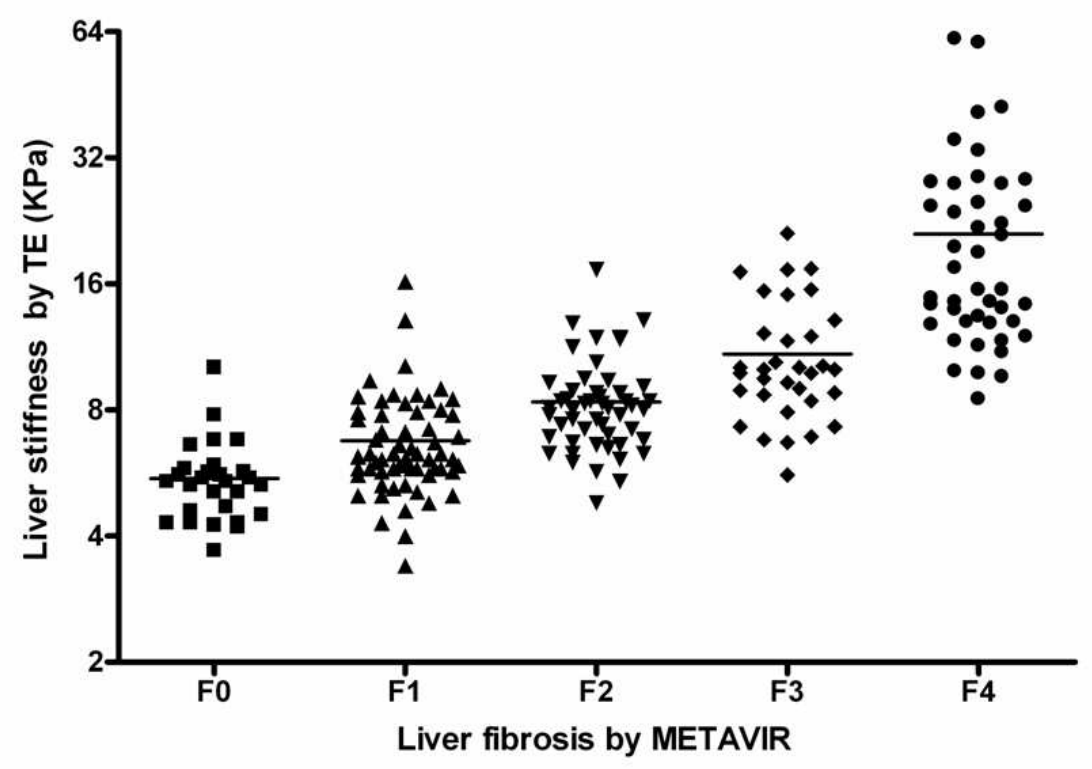

\footnotetext{
Distribution of liver stiffness ( $\mathrm{kPa}$ ) values using transient elastography according to METAVIR staging score in 217 patients. 254x190mm (96 x 96 DPI)
} 
Figure $2 a$

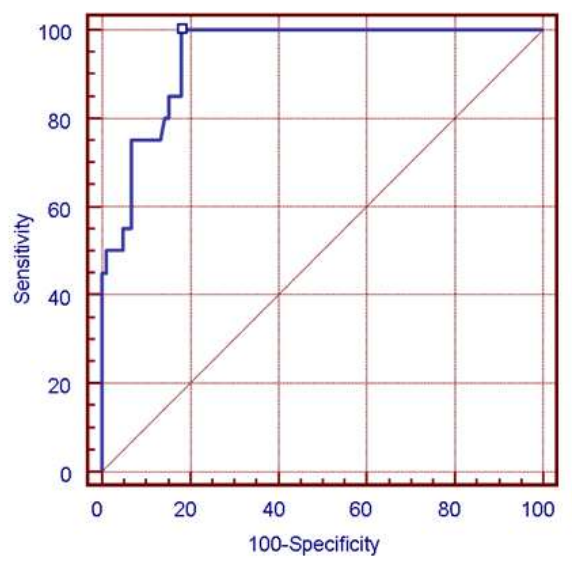

Figure $2 b$

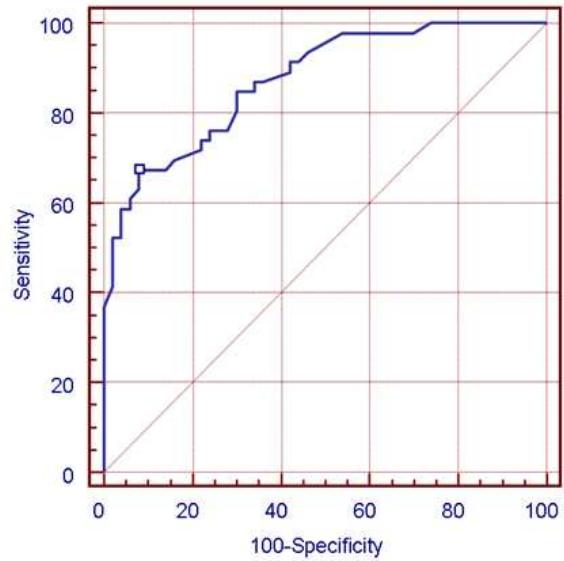

A) ROC curve representing the relationship between sensitivity and 1 - specificity of liver stiffness for the diagnosis of cirrhosis (F4). The white square represents the cut-off value with the highest accuracy, i.e. $9.4 \mathrm{kPa}$ (sensitivity $100 \%$, specificity $82 \%$ ).

B) ROC curve representing the relationship between sensitivity and 1 - specificity of liver stiffness for significant fibrosis $(F \geq 2)$. The white square represents cut-off value with the highest accuracy, i.e. $8.7 \mathrm{kPa}$ (sensitivity $63.6 \%$, specificity $91.5 \%$ ). 
Figure S1

10

39

40

41

42

43

44

45

46

47

48

49

50

51

52

53

54

55

56

57

58

59

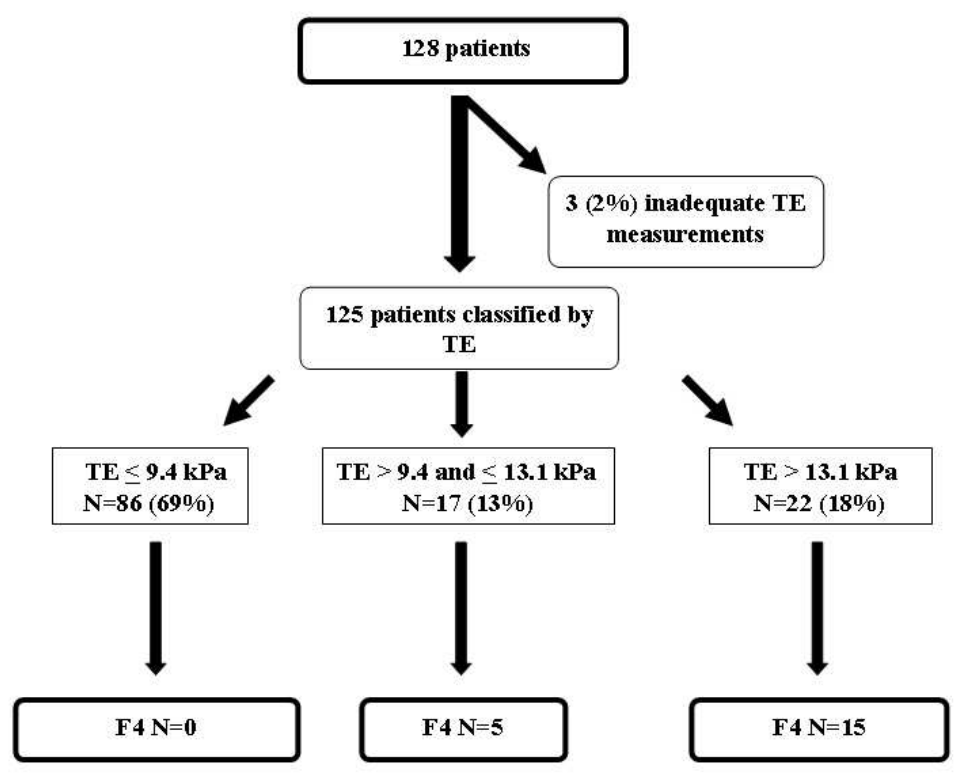

Training cohort of 125 patients. Diagnostic algorithm to confirm or exclude cirrhosis (F4) by transient elastography. Post-test probability of cirrhosis is the proportion of patients with histological diagnosis of cirrhosis according to transient elastography classification. $254 \times 190 \mathrm{~mm}(96 \times 96$ DPI) 


\section{$x$}

Validation cohort of 92 patients. Diagnostic algorithm to confirm or exclude cirrhosis (F4) by transient elastography. Post-test probability of cirrhosis is the proportion of patients with histological diagnosis of cirrhosis according to transient elastography classification. $254 \times 190 \mathrm{~mm}(96 \times 96 \mathrm{DPI})$ 
Figure S3

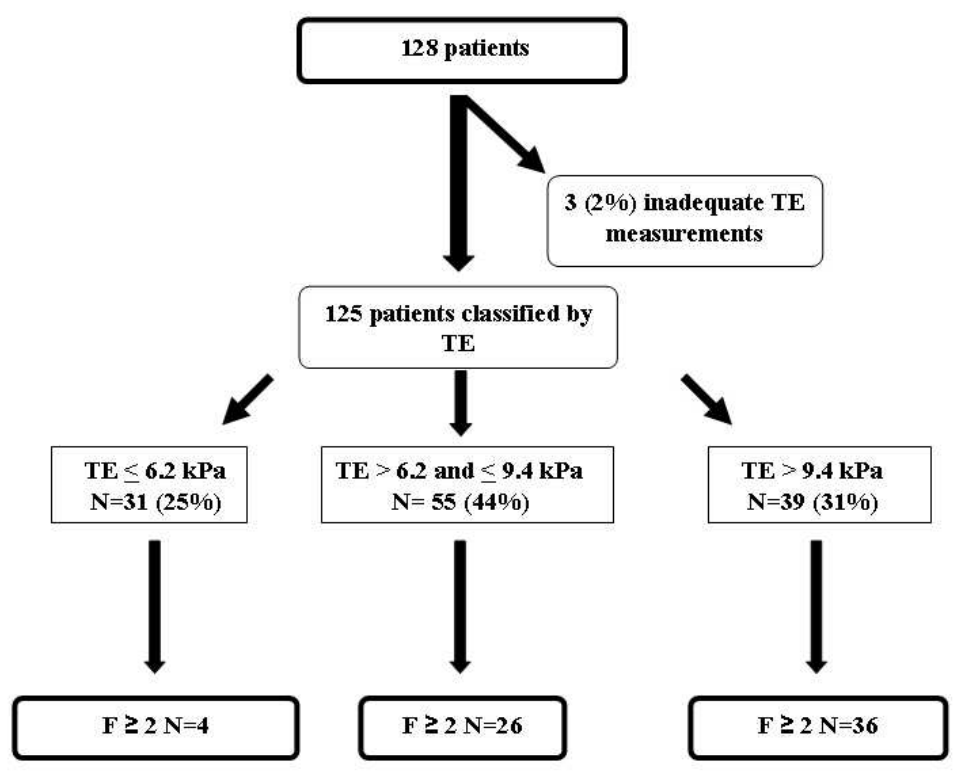

Training cohort of 125 patients. Diagnostic algorithm to confirm or exclude significant fibrosis ( $F \geq$ 2) by transient elastography. Post-test probability of significant fibrosis is the proportion of patients with histological diagnosis of $\mathrm{F} \geq 2$ according to transient elastography classification. 
Figure S4

Validation cohort of 92 patients. Diagnostic algorithm to confirm or exclude significant fibrosis ( $F \geq$ 2) by transient elastography. Post-test probability of significant fibrosis is the proportion of patients with histological diagnosis of $F \geq 2$ according to transient elastography classification. $254 \times 190 \mathrm{~mm}(96 \times 96 \mathrm{DPI})$ 